\title{
No Calcium-Fluoride-Like Deposits Detected in Plaque Shortly after a Sodium Fluoride Mouthrinse
}

\author{
G.L. Vogel $^{\mathrm{a}} \quad$ L.M.A. Tenuta ${ }^{\mathrm{b}}$ G.E. Schumacher ${ }^{\mathrm{a}} \quad$ L.C. Chow ${ }^{\mathrm{a}}$ \\ ${ }^{a}$ American Dental Association Foundation, Paffenbarger Research Center, Gaithersburg, Md., USA; \\ ${ }^{b}$ Piracicaba Dental School, University of Campinas, Piracicaba, Brazil
}

Key Words

Calcium • Fluoride $\cdot$ Fluoride binding • Plaque

\begin{abstract}
Plaque 'calcium-fluoride-like' ( $\mathrm{CaF}_{2}$-like) and fluoride deposits held by biological/bacterial calcium fluoride (Ca-F) bonds appear to be the source of cariostatic concentrations of fluoride in plaque fluid. The aim of this study was to quantify the amounts of plaque fluoride held in these reservoirs after a sodium fluoride rinse. 30 and $60 \mathrm{~min}$ after a $228 \mu \mathrm{g} / \mathrm{g}$ fluoride rinse, plaque samples were collected from 11 volunteers. Each sample was homogenized, split into 2 aliquots (aliquots 1 and 2), centrifuged, and the recovered plaque fluid combined and analyzed using microelectrodes. The plaque mass from aliquot 1 was retained. The plaque mass from aliquot 2 was extracted several times with a solution having the same fluoride, calcium and $\mathrm{pH}$ as the plaque fluid in order to extract the plaque $\mathrm{CaF}_{2}$-like deposits. The total fluoride in both aliquots was then determined. In a second experiment, the extraction completeness was examined by applying the above procedure to in vitro precipitates containing known amounts of $\mathrm{CaF}_{2}$-like deposits. Nearly identical fluoride concentrations were found in both plaque aliquots. The extraction of the $\mathrm{CaF}_{2}$-like precipitates formed in vitro removed more than $80 \%$ of these deposits. The results
\end{abstract}

suggest that either $\mathrm{CaF}_{2}$-like deposits were not formed in plaque or, if these deposits had been formed, they were rapidly lost. The inability to form persistent amounts of $\mathrm{CaF}_{2}$-like deposits in plaque may account for the relatively rapid loss of plaque fluid fluoride after the use of conventional fluoride dentifrices or rinses.

Copyright ๑ 2010 S. Karger AG, Basel

Based on laboratory [Margolis and Moreno, 1990; ten Cate, 1990] and clinical observations (reviewed by Featherstone [2000]), current models for increasing the anticaries effects of fluoride (F) agents emphasize the importance of maintaining a cariostatic concentration of $F$ in oral fluids. Given the role of plaque in the caries process, this emphasis has focused attention on the 'bioavailable' plaque $F$ reservoirs that persistently increase the F concentrations in the fluid phase of plaque (the plaque fluid).

Certain commercial materials and equipment are identified in this paper to specify the experimental procedure. In no instance does such identification imply recommendation or endorsement by the National Institute of Standards and Technology or the American Dental Association Foundation or that the material or the equipment identified is necessarily the best available for the purpose.

\section{KARGER}

() 2010 S. Karger AG, Basel

Fax +41613061234 E-Mail karger@karger.ch www.karger.com www.karger.com/cre
Dr. Gerald Vogel

American Dental Association Foundation, Paffenbarger Research Center 100 Bureau Drive Stop 8546, National Institute of Standards and Technology Gaithersburg, MD 20899-8546 (USA)

Tel. +1 301975 6821, Fax +1 301963 9143,E-Mail jvogel@ nist.gov 
These F reservoirs can be divided into 2 broad types, both of which involve calcium $(\mathrm{Ca})$ : the mineral calcium fluoride $\left(\mathrm{CaF}_{2}\right)$ and biologically/bacterially bound calcium fluoride deposits in which $\mathrm{F}$ is held by $\mathrm{Ca}$ ions bound on the surface of these entities.

In an extensive study of bacterial $\mathrm{F}$ binding, referred to here as bacterial Ca-F, Rose et al. [1996] proposed a model in which $\mathrm{F}$ reacts with intercellular or intracellular $\mathrm{Ca}$ 'bridges' to form Ca-F bonds at fixed anionic bacterial sites. These authors found that plaque bacterial Ca-F binding was a function of the plaque fluid $\left\{\mathrm{Ca}^{2+}\right\}$ and $\left\{\mathrm{F}^{-}\right\}$where \{\} refers to the chemical activities of these ions (the chemical activity is the free, unbound concentration of an ion multiplied by an ionic-strength-dependent constant [Vogel et al., 1990b]). Bacterial Ca-F binding was also found to be a function of the activities of the binding moieties (essentially the number of binding sites) and the $\mathrm{pH}$ [Rose et al., 1996]. The $\mathrm{pH}$ dependence is a consequence of the competition of $\mathrm{Ca}^{2+}$ and $\mathrm{H}^{+}(\mathrm{pH}=$ $-\log \left\{\mathrm{H}^{+}\right\}$) for the same anionic sites on the bacterial surface [Rose et al., 1996]. Because bacterial Ca-F is a continuous function of these activities, exposure of a plaque sample to a plaque-fluid-like solution with the same $\left\{\mathrm{Ca}^{2+}\right\},\left\{\mathrm{F}^{-}\right\}$and $\mathrm{pH}$ as the plaque fluid recovered from this sample should not alter bacterial Ca-F.

Calcium fluoride (i.e. $\mathrm{CaF}_{2}$ ) has also been suggested as an important plaque $\mathrm{F}$ reservoir. Some researchers have suggested, given the labile nature of plaque Ca reservoirs, that this mineral should be formed in plaque by the same Ca scavenging known to occur when high $\mathrm{F}$ concentrations are applied to enamel [ten Cate, 1997; Øgaard, 2001]. Others have suggested that calcium fluoride could form in plaque by a reaction of the applied $\mathrm{F}$ with the plaque fluid Ca [Matsuo et al., 1990; Larsen and Richards, 2001; Øgaard, 2001] or by a reaction of $\mathrm{F}$ with salivary Ca followed by a migration of the $\mathrm{CaF}_{2}$ into or onto the plaque [Larsen and Ravnholt, 1994; Whitford et al., 2005].

Calcium fluoride dissolution (and formation), in contrast to the behavior of bacterial Ca-F, is an all-ornothing function in which dissolution/formation occurs when the ion activity product (IAP) of this mineral $\left(\mathrm{IAP}_{\text {calcium fluoride }}=\left\{\mathrm{Ca}^{2+}\right\} \times\left\{\mathrm{F}^{-}\right\}^{2}\right)$ is below/above a constant called the solubility product $\left(\mathrm{KSP}_{\text {calcium fluoride }}=3 \times\right.$ $10^{-11}$ ) [McCann, 1968]. Hence, if the Ca and F concentrations of a fluid in contact with the plaque are such that the $\left\{\mathrm{Ca}^{2+}\right\} \times\left\{\mathrm{F}^{-}\right\}^{2}$ is lower than $3 \times 10^{-11}$, then in theory all the $\mathrm{CaF}_{2}$ in the plaque will dissolve. Although $\left\{\mathrm{H}^{+}\right\}$ (i.e. $\mathrm{pH}$ ) should in theory play no part in this dissolution at a $\mathrm{pH}$ value greater than approximately 5 , pure calcium fluoride exposed to saliva appears to have a slow rate of dissolution, apparently due to a surface reaction with $\mathrm{pH}$ sensitive oral fluid phosphates [Christoffersen et al., 1988; Arends and Christoffersen, 1990; Rølla and Saxegaard, 1990; ten Cate, 1997; Øgaard, 2001]. It should be noted, however, that several studies suggest a much higher rate of dissolution for the type of phosphate-containing $\mathrm{CaF}_{2}$ deposits formed in the oral environment [Christoffersen et al., 1988; Larsen and Ravnholt, 1994]. In the current paper, these phosphate-contaminated calcium fluoride deposits are referred to, in accordance with other authors [Larsen and Richards, 2001], as 'calcium-fluoride-like' $\left(\mathrm{CaF}_{2}\right.$-like). In any case, because these deposits are actually more soluble than pure calcium fluoride [Christoffersen et al., 1988], any type of calcium fluoride formed in plaque should rapidly dissolve in a phosphate-free plaque-fluid-like solution, provided that the $\mathrm{F}$ and $\mathrm{Ca}$ concentrations reflect the plaque fluid values obtained when the $\mathrm{IAP}_{\text {calcium fluoride }}$ is significantly lower than the

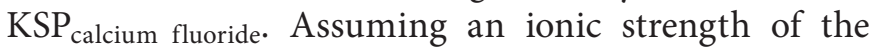
plaque fluid of about $150 \mathrm{mmol} / \mathrm{l}$ [Vogel et al., 1998, 2000b], and a free or unbound calcium concentration in the plaque fluid of $0.9 \mathrm{mmol} / \mathrm{l}$ [Vogel et al., 1998, 2000b, $2002]$, the critical value of free $\mathrm{F}$ that will induce a dissolution of pure calcium fluoride or $\mathrm{CaF}_{2}$-like deposits can be calculated to be about $450 \mu \mathrm{mol} / \mathrm{l}$ (Chemist, Salt Lake City, Utah, USA). Postrinse plaque fluid free F concentrations usually fall well below this value within $0.5 \mathrm{~h}$ after use of a $228 \mu \mathrm{g} / \mathrm{g}$ F rinse [Vogel et al., 1992, 2000a], and hence $0.5 \mathrm{~h}$ after a NaF rinse, any calcium fluoride found in the plaque should begin to be lost by dissolution into plaque fluid. This dissolution is, as described above, relatively rapid, even in the case of pure calcium fluoride, if the phosphate content of the fluid in contact with the plaque is very low.

The purpose of this study was to use the different dissolution properties of plaque $\mathrm{CaF}_{2}$-like and bacterial Ca-F deposits described above to quantify the amounts of these plaque deposits after the use of a NaF rinse. The quantification procedure relies upon the observation described above: a plaque sample exposed to a very-lowphosphate plaque-fluid-like solution with the same $\left\{\mathrm{Ca}^{2+}\right\},\left\{\mathrm{F}^{-}\right\}$and $\mathrm{pH}$ as the plaque fluid recovered from this sample more than $0.5 \mathrm{~h}$ after a $\mathrm{F}$ rinse should dissolve all the calcium fluoride deposits. The plaque F deposits not altered by this procedure (i.e. deposits that are in equilibrium with their fluid environment) are taken here to be in the form of bacterial Ca-F. Although this description of bacterial $\mathrm{F}$ binding is in accordance with the model described above, it should be noted that this type of $\mathrm{Ca}-\mathrm{F}$ binding may also include $\mathrm{F}$ bound to bacterial frag- 
ments and proteins as well as insoluble mineral deposits such as fluorapatite (FAp) that should not be extracted by this procedure.

\section{Subjects and Methods}

Subject Protocol, Rinse Administration and Sample Collection

Rinse administration and the collection of samples were done with the informed consent of the subjects following protocols reviewed and approved by the appropriate institutional review boards. The 11 subjects ( 9 males, 2 females; age range: 24-56 years; mean age: 40.3 years) were screened before participation to ensure good oral health (no signs of neglect or untreated decay) and normal salivary gland function (unstimulated salivary flow rate of $>0.2 \mathrm{~g} / \mathrm{min})$. All subjects lived in an area with fluoridated water (2007 average $\mathrm{F}=0.99 \mu \mathrm{g} / \mathrm{g}$; range: $0.49-1.3 \mu \mathrm{g} / \mathrm{g}$; all experiments were done in March 2007). Before each experiment, the participants accumulated plaque for $48 \mathrm{~h}$ and fasted overnight. During the 48-hour plaque accumulation, the subjects were instructed to avoid tooth brushing, flossing, the use of mouth rinses, chewing gums and tea (some teas contain high amounts of F). In the morning, the subjects rinsed with $20 \mathrm{ml}$ of an aqueous $\mathrm{F}$ solution for $1 \mathrm{~min}$. The F rinse concentration of this solution, 228 $\mu \mathrm{g} / \mathrm{g} \mathrm{F}$ as NaF, was chosen because it is similar to the concentration used in over-the-counter F rinses. Plaque samples were then obtained $0.5 \mathrm{~h}$ and $1 \mathrm{~h}$ later. The choice of the 0.5 -hour collection time was, as noted in the introduction, dictated by the requirement of the analysis procedure. The 60 -min time point was used because this plaque collection time has been used in a large number of previous studies [Vogel et al., 1992, 2000a, 2000c, 2001, $2008 \mathrm{~b}$ ] and because changes in the amount of $\mathrm{CaF}_{2}$-like deposits between these time points may address questions about the rate of dissolution of these deposits in the oral environment noted in the introduction. As described below, each recovered plaque sample was split into 2 nearly identical aliquots.

Recovery of 2 Identical Aliquots of Homogenized Plaque from a Single Plaque Sample

The procedure used to recover 2 homogenized, 'matched' plaque samples from each subject is a modification of procedures previously employed [Vogel et al., 1998, 2000a, 2002, 2008b], in which water-saturated $5 \% \mathrm{CO}_{2} / 95 \%$ nitrogen gas (volume ratio; $\mathrm{WSCO}_{2}-\mathrm{N}_{2}$ gas) is used to prevent evaporation or $\mathrm{pH}$ changes due to $\mathrm{CO}_{2}$ loss from the plaque. First, a plastic strip and microcentrifuge tube containing mineral oil that was equilibrated with WSCO ${ }_{2}-\mathrm{N}_{2}$ gas were weighed together on a microbalance. The strip was then grasped in a hemostat. This process was next repeated, so that 2 weighed strips/oil-filled centrifuge tubes were obtained. Second, one strip was used to collect a post-treatment molar plaque sample from the easily accessible buccal surfaces of all first and second molar/premolar teeth. Third, this strip/plaque sample was then inserted into one port of a $25-\mathrm{mm}$ clear acrylic tube (fig. 1) which was flushed with $\mathrm{WSCO}_{2}-\mathrm{N}_{2}$ gas, and transferred to a plastic-film-covered rubber stopper at the bottom of the tube. Fourth, the second hemostat was inserted through a second port in the acrylic tube and the 2 strips used to gently knead/ homogenize the plaque for $30 \mathrm{~s}$. Fifth, after this homogenization, the plaque was split into 2 approximately equal parts (aliquots 1

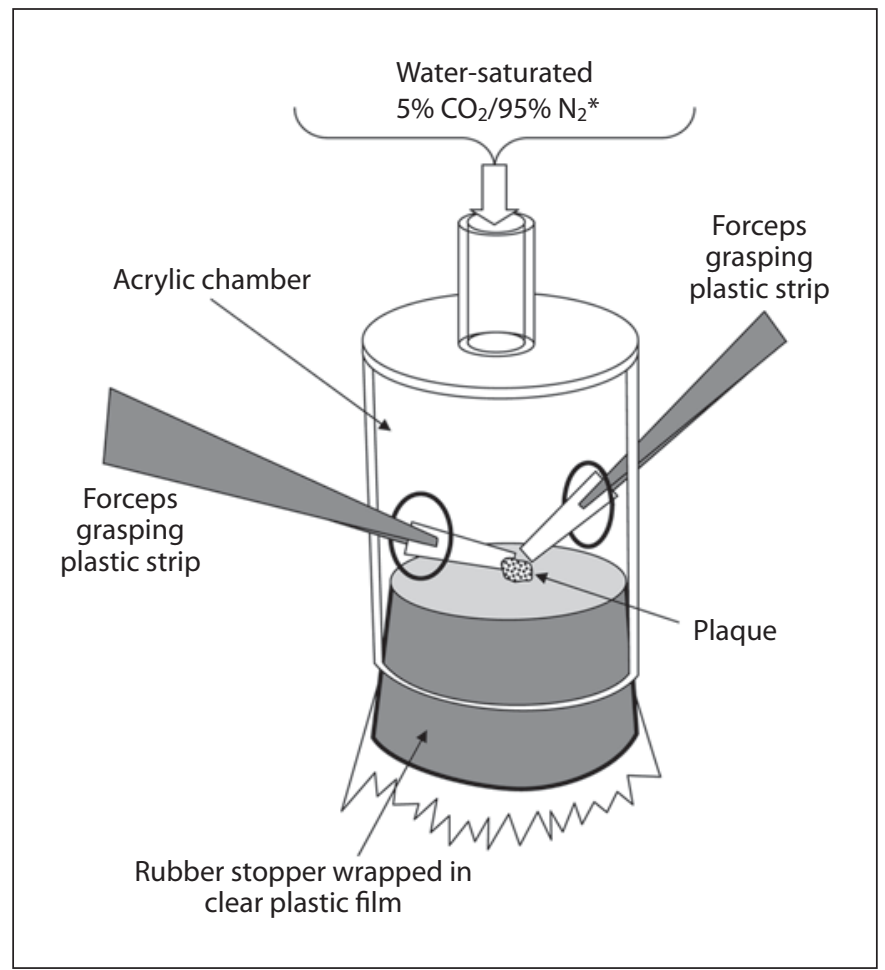

Fig. 1. Apparatus for homogenization and splitting of plaque samples. ${ }^{*}$ Volume ratio.

and 2) and collected on the 2 plastic strips. Finally, each strip with its plaque sample was transferred to its corresponding oil-filled microcentrifuge tube and reweighed to determine the masses of the 2 samples. These samples were then stored, in an ice bath, for $0.5 \mathrm{~h}$ to allow for equilibration of the $\mathrm{F}$ between the bacterial $\mathrm{Ca}-\mathrm{F}$ and the plaque fluid. One of the plaque aliquots (aliquot 1) was retained for the determination of the total $\mathrm{F}$ content, while the second (aliquot 2) was extracted, as described below, using a procedure designed to extract all the calcium fluoride or $\mathrm{CaF}_{2}$-like deposits from the sample.

\section{Recovery and Analysis of Plaque Fluid and Plaque}

The 2 matched plaque aliquots were centrifuged, as described above, and the plaque fluid recovered from the microcentrifuge tubes with capillary micropipettes. The fluid samples from the 2 aliquots were then combined, recentrifuged in a new microcentrifuge tube to remove any traces of plaque, and the fluid recovered for analysis. (Due to the relatively small amount of ions in the plaque fluid relative to the plaque mass, removal of the plaque fluid does not significantly reduce the plaque $\mathrm{Ca}$ or $\mathrm{F}$ content). Microelectrode techniques were used for the plaque fluid analysis. These techniques have been extensively described and are only summarized here [Vogel et al., 1990a, 1990b, 2000c]. The samples contained in the micropipette were deposited, with the aid of a stereomicroscope, on the surface of an inverted fluoride electrode that was covered with WSCO$-\mathrm{N}_{2}$-gas-equilibrated mineral oil. The circuit from the fluoride electrode to a high-impedance elec- 
trometer (World Precision Instruments, Sarasota, Fla., USA) was then completed by contacting these samples with a reference microelectrode held in a micropositioning device. For $\mathrm{Ca}$ and $\mathrm{pH}$ measurements, micro $\mathrm{Ca}$ and $\mathrm{pH}$ electrodes, made by trapping an ion-selective liquid in the tip of a fine (approx. $10 \mu \mathrm{m}$ diameter) glass capillary [Vogel et al., 1990b, 2000c], were brought into contact with the sample and the circuit completed with the same reference electrode used for the F measurements. Fluoride and calcium standards used in calibrating these electrodes were made by adding concentrated $\mathrm{Ca}$ and $\mathrm{F}$ solutions to a $50 \mathrm{mmol} / \mathrm{l}, \mathrm{pH} 6.84$ PIPES (Sigma Aldrich, St. Louis, Mo., USA) buffer containing 41.6 $\mathrm{mmol} / \mathrm{l}$ of $\mathrm{KCl}$. This plaque-fluid-like solution has a $\mathrm{pH}$ and ionic strength that is similar to resting plaque fluid (noted above); however, moderate deviations from the ionic strength of the plaque samples would have only a minor effect on the results. The pH standards (Fisher Scientific, Pittsburg, Pa., USA) were also deposited under mineral oil on the surface of the electrode. However, since their $\mathrm{pH}$ was altered by exposure to the $\mathrm{CO}_{2}$ in the mineral oil, their actual $\mathrm{pH}$ was first determined by a conventional electrode after equilibration with $\mathrm{WSCO}_{2}-\mathrm{N}_{2}$ gas.

\section{Procedure for Measuring Plaque $\mathrm{CaF}_{2}$-Like and Bacterial}

\section{Ca-F Deposits in Postrinse Plaque Samples}

After fluid removal, the tips of the 2 microcentrifuge tubes containing the plaque aliquots were cut with a razor blade and the plaque masses (and mineral oil) expelled by momentary centrifugation into two 500- $\mu$ l plastic centrifuge tubes. A plaque-fluidlike solution was made up in the background plaque fluid buffer (above), containing the same $\left\{\mathrm{Ca}^{2+}\right\},\left\{\mathrm{F}^{-}\right\}$and $\mathrm{pH}$ as measured in each plaque fluid sample. This solution also contained $10 \mu \mathrm{mol} / \mathrm{l}$ of sodium pyrophosphate to suppress the formation of FAp [Moreno et al.,1987], which at least in theory might occur as a result of phosphate release from the plaque mass. A $250-\mu l$ plastic pipette tip was used to stir $75 \mu$ l of the plaque-fluid-like solution into plaque aliquot 2 [Vogel et al., 2008b] for about $1 \mathrm{~min}$. After $15 \mathrm{~min}$, the tube was centrifuged and the solution volume over the plaque carefully reduced to approximately $5 \mu \mathrm{l}$ using a fine capillary. The above equilibration/mixing and centrifugation/fluid removal was then repeated. Next, $500 \mu \mathrm{l}$ of the plaque-fluid-like solution was slowly added to the tube, and the fluid centrifuged into contact with the plaque mass (i.e. without mixing). The mineral oil above the fluid was then vacuumed away, after which the slight amount of oil remaining on the surface of the fluid was removed by washing with 2 hexane rinses. After the hexane had evaporated, the tube was closed, and 45 min later, the fluid above the plaque mass was again reduced and another $500 \mu$ l volume of the plaque-fluid-like solution centrifuged into contact with the plaque mass. Finally, after another 1-hour equilibration/extraction, the fluid volume over the plaque was again reduced to approximately $5 \mu \mathrm{l}$. This film of fluid over the plaque was used as a probe to test for the completeness of the equilibration/extraction with the plaque-fluid-like solution; the fluid was allowed to remain in contact with the plaque for approximately $2 \mathrm{~h}$, after which the $\left\{\mathrm{F}^{-}\right\}$content was determined. If the $\left\{\mathrm{F}^{-}\right\}$in this fluid was more than $10 \%$ greater than the $\left\{\mathrm{F}^{-}\right\}$in the plaque-fluid-like solution with which the plaque was equilibrated, then the equilibration was taken to be incomplete (i.e. fluoride continued to be released). Hence, another series of the equilibration with $500 \mu \mathrm{l}$ of plaquefluid-like solution was started. Additionally, since phosphate might greatly increase the time to reach equilibrium, the phos- phate content of this 5 - $\mu$ l volume was estimated colorimetrically [Vogel et al., 1983] and the equilibration continued if the phosphate was higher than $10 \mu \mathrm{mol} / \mathrm{l}$. Following this procedure, the minimum time of exposure of the plaque to the plaque-fluid-like solution was about $4 \mathrm{~h}$.

When the above test conditions were met and the extraction was considered to be complete, the total $\mathrm{F}$ in this aliquot (aliquot 2) and in the unextracted aliquot (aliquot 1) was extracted by treating the plaque mass with $25 \mu \mathrm{l} / \mathrm{mg}$ of $1 \mathrm{~mol} / \mathrm{l}$ of perchloric acid for $1 \mathrm{~h}$ [Vogel et al., 2008b]. This mixture was then neutralized by adding an identical volume of $1 \mathrm{~mol} / \mathrm{l}$ of $\mathrm{NaOH}$ containing $20 \%$ (volume ratio) TISAB III (total ionic strength adjustment buffer; Thermo Orion, Cambridge, Mass., USA) and centrifuging for $5 \mathrm{~min}$ as described above. The plaque acid extracts were then analyzed using the inverted fluoride electrode procedure noted above.

\section{In vitro Test of Extraction Procedure}

Although our plaque-like extraction solutions did not contain phosphate, low concentrations of this ion (maximally about 10 $\mu \mathrm{mol} / \mathrm{l}$; see above) are generally released into this fluid from plaque phosphate reservoirs during the equilibration. Furthermore, as noted, these solutions contain $10 \mu \mathrm{mol} / \mathrm{l}$ of pyrophosphate. Low concentrations of either of these ions can greatly suppress the rate of dissolution of chemically pure calcium fluoride [Lagerlöf et al., 1988]. If this suppression were high enough, the extraction procedure described above for $\mathrm{CaF}_{2}$-like deposits would be completely ineffective. In order to address this possibility, the following study was undertaken.

Two identical suspensions of type-1-phosphate-contaminated $\mathrm{CaF}_{2}$-like deposits were prepared as described by Christoffersen et al. [1988] and aged more than $3 \mathrm{~h}$ before use. This type of $\mathrm{CaF}_{2}-$ like deposit was employed because it is formed in the presence of calcium, phosphate and fluoride concentrations that approximately duplicate [Vogel et al., 1998, 2000b] the in vivo salivary concentration of these ions about $2 \mathrm{~min}$ after the use of the 12 $\mathrm{mmol} / \mathrm{l} \mathrm{NaF}$ rinse used here $\left(\mathrm{Ca}=4 \mathrm{mmol} / \mathrm{l} ; \mathrm{PO}_{4}=2.4 \mathrm{mmol} / \mathrm{l}\right.$; $\mathrm{F}=5 \mathrm{mmol} / \mathrm{l}$ ). Two portions of this suspension were formed. The first was centrifuged for $15 \mathrm{~min}$ and the fluid carefully recovered (i.e. leaving the $\mathrm{CaF}_{2}$-like deposits behind). This fluid is saturated with $\mathrm{CaF}_{2}$-like material and, hence, should not dissolve this mineral. The second portion was rapidly stirred, and $10-\mu l$ aliquots were dispensed into sixteen $500-\mu$ l centrifuge tubes and divided into 4 groups (4 tubes each). One of these groups (group 1) was retained for a determination of the total $\mathrm{F}$ content of the sample, while the remaining 3 groups were extracted, following the above procedure, with a total extraction time equal to the minimum extraction time of the plaque samples (i.e. $4 \mathrm{~h}$ ). The group 2 tubes were extracted with a plaque-like solution with $\mathrm{F}$ and $\mathrm{Ca}$ concentrations $(0.050 \mathrm{mmol} / \mathrm{l}$ and $1 \mathrm{mmol} / \mathrm{l}$, respectively) that were similar to what we had observed in studies of plaque collected 30-60 min after a $12 \mathrm{mmol} / \mathrm{l} \mathrm{F}$ rinse [Vogel et al., 1992, 2000a, 2000c, 2001]. This solution also contained (as in the current study) 10 $\mu \mathrm{mol} / \mathrm{l}$ of sodium pyrophosphate. The group 3 tubes were extracted with a similar solution, but this one also contained 10 $\mu \mathrm{mol} / \mathrm{l}$ of phosphate (i.e. a concentration similar to the maximum plaque phosphate permitted in the current study). It should be noted that the fluid volume was reduced to about $10 \mu \mathrm{l}$ between the steps of the extraction because a more extensive fluid removal might increase the bulk loss of the $\mathrm{CaF}_{2}$-like deposits at the 
Table 1. Masses of 2 nominally identical plaque aliquots $(n=11$ pairs) obtained after $\mathrm{F}(\mathrm{NaF})$ rinse

\begin{tabular}{lllll}
\hline $\begin{array}{l}\text { Time } \\
\text { min }\end{array}$ & $\begin{array}{l}\text { Aliquot 1 } \\
\text { plaque mass, mg }\end{array}$ & $\begin{array}{l}\text { Aliquot 2 } \\
\text { plaque mass, mg }\end{array}$ & $\begin{array}{l}{\left[\mathrm{Ca}^{2+}\right]} \\
\mathrm{mmol} / \mathrm{l}\end{array}$ & $\mathrm{pH}$ \\
\hline 30 & $2.24 \pm 0.20$ & $2.42 \pm 0.27$ & $0.70 \pm 0.12$ & $6.66 \pm 0.07$ \\
60 & $2.77 \pm 0.22$ & $2.76 \pm 0.31$ & $0.80 \pm 0.31^{1}$ & $6.73 \pm 0.08$ \\
\hline
\end{tabular}

The data are given as means $\pm \mathrm{SE}$. The aliquot masses were obtained after a $228 \mu \mathrm{g} / \mathrm{g} \mathrm{F}(\mathrm{NaF})$ rinse. The free calcium $\left[\mathrm{Ca}^{2+}\right]$ concentration and $\mathrm{pH}$ of pooled plaque fluid samples obtained from these 2 aliquots are also presented. There were no statistically significant differences ( $\mathrm{p}>0.05$; two-way ANOVA for plaque masses; paired difference test for $\mathrm{pH}$ and $\left[\mathrm{Ca}^{2+}\right]$ ).

${ }^{1} \mathrm{n}=10$. One $\left[\mathrm{Ca}^{2+}\right]$ value at $60 \mathrm{~min}$ was an outlier by the criteria of Grubbs and Beck [1972] and was omitted. The omitted value was $2.0 \mathrm{mmol} / \mathrm{l}$.

bottom of the tube. However, in order to insure that an excessive bulk removal of these crystals had not occurred, the tubes in the remaining group (group 4) were similarly extracted with the $\mathrm{CaF}_{2}$-like saturated solution (which, in theory, should not dissolve these crystals). After the final fluid removal, the $\mathrm{F}$ in the tubes was determined as described above (applying a small correction for the known amount of $\mathrm{F}$ in the $10 \mu \mathrm{l}$ of fluid left in each tube).

\section{Calculation of Free Calcium and Free Fluoride}

Although calcium and fluoride activities, denoted above as $\left\{\mathrm{Ca}^{2+}\right\}$ and $\left\{\mathrm{F}^{-}\right\}$, are used in the calculation of ion binding, the free ion concentrations, denoted as $\left[\mathrm{Ca}^{2+}\right]$ and $\left[\mathrm{F}^{-}\right]$below and in tables 1 and 2, are more commonly presented because they represent the fraction of the total concentration in solution that is unbound or uncomplexed. As noted above, the ion activity is the free ion concentration multiplied by an ionic-strength-dependent coefficient. These coefficients, calculated using the Bockris-Reddy equation [Bockris and Reddy, 2000], were 0.37 for calcium and 0.75 for fluoride (assuming a plaque fluid ionic strength of about $150 \mathrm{mmol} / \mathrm{l})$

\section{Statistical Procedures}

A significance level of $\mathrm{p}<0.05$ was used in all statistical tests which were performed using the SigmaStat software (Systat Software Inc., San Jose, Calif., USA). The data for the in vitro test of the extraction procedure, the plaque fluid free $\mathrm{Ca}^{2+}, \mathrm{pH}^{1}$ values and the plaque masses were normally distributed and are hence presented (table 1) as means \pm standard error (SE). Differences in plaque fluid calcium concentration and $\mathrm{pH}$ between the 2 collec-

$1 \mathrm{pH}$ is defined as $-\log \left\{\mathrm{H}^{+}\right\}$. The average $\mathrm{pH}$ is calculated here as the mean of the $\mathrm{pH}$ values rather than the average of the $\left\{\mathrm{H}^{+}\right\}$values [Margolis et al., 1993].
Table 2. Total fluoride content of 2 nominally identical plaque aliquots ( $n=11$ pairs) obtained after $\mathrm{F}(\mathrm{NaF})$ rinse

\begin{tabular}{llll}
\hline $\begin{array}{l}\text { Time } \\
\text { min }\end{array}$ & $\begin{array}{l}\text { Aliquot 1 } \\
\text { (total F), } \mu \mathrm{mol} / \mathrm{g}\end{array}$ & $\begin{array}{l}\text { Aliquot 2 (bacterial } \\
\text { Ca-F), } \mu \mathrm{mol} / \mathrm{g}\end{array}$ & $\begin{array}{l}\text { Plaque } \\
\text { fluid }\left[\mathrm{F}^{-}\right], \mu \mathrm{mol} / \mathrm{l}\end{array}$ \\
\hline 30 & $1.61(0.022)$ & $1.60(0.023)$ & $85(0.55)$ \\
60 & $1.39(0.020)$ & $1.43(0.020)$ & $22(0.38)$ \\
\hline
\end{tabular}

The data are given as geometric means, with standard error factors in parentheses. The aliquot masses were obtained after a $228 \mu \mathrm{g} / \mathrm{g} \mathrm{F}(\mathrm{NaF})$ rinse. Aliquot 1 contained the total $\mathrm{F}$ in the sample, while aliquot 2 was extracted under conditions that removed all forms of $\mathrm{CaF}_{2}$. The free fluoride $\left[\mathrm{F}^{-}\right]$concentration of pooled plaque fluid samples obtained from these aliquots is also presented. There are no statistical differences between the total F content for the plaque aliquots ( $\mathrm{p}>0.05$; two-way ANOVA). The plaque fluid $\left[\mathrm{F}^{-}\right]$values were different between the $30 \mathrm{~min}$ and 60 min time points ( $\mathrm{p}<0.01$; Student's $\mathrm{t}$ test).

tion times were examined by a paired difference test. The amount of $\mathrm{F}$ remaining in groups 2, 3 and 4 after the in vitro extraction procedure was examined by a one-way ANOVA and the NewmanKeuls multiple comparison method. The consistency of the plaque collection and homogenization procedure was examined by comparing the plaque masses using a two-way ANOVA with time (30 and $60 \mathrm{~min}$ ) and aliquot number (aliquot 1 and 2) as factors. A two-way ANOVA was also used to examine, at the 2 collection times, the F content of plaque aliquots 1 and 2, while the Student $\mathrm{t}$ test was used to examine plaque fluid $\mathrm{F}$ (table 2). However, as in previous studies [Vogel et al., 2000a, 2006, 2008b; Whitford et al., 2005], the fluoride data needed to be 'normalized' by a logarithmic transformation in order to use these parametric statistics. For this same reason, and in accordance with other studies, the geometric means of the F values and the standard deviation factor are presented as the F data of table 2 rather than the means and SE [Vogel et al., 2006, 2008a]. The use of the geometric mean has the advantage of suppressing the influence of the positive outliers which are common in fluoride values collected shortly after administration. Similarly, because of the non-normal data distribution, the association between the F concentrations obtained at the 30 - or 60-min sample collection times was examined using the Spearman rank-order correlation. The SE (given after the \pm symbol) or the standard error factor (given in parentheses) are used here as measures of the standard uncertainty.

\section{Results}

In the in vitro test for the extraction procedure, the total $\mathrm{F}$ delivered to the samples, as shown by the analysis of the group 1 samples, was $0.03926 \pm 0.00032 \mu \mathrm{mol}$, which is similar to the amount of $\mathrm{F}(0.05 \mu \mathrm{mol})$ calculated for these in vitro samples. The amount of $F$ remain- 
ing after extraction with the solution saturated with respect to the phosphate-contaminated $\mathrm{CaF}_{2}$-like deposits (group 4) was $0.0249 \pm 0.0019 \mu \mathrm{mol}$. Hence, about $37 \%$ of the $\mathrm{F}$ delivered to the tubes was lost, apparently by a bulk removal of these fine crystals during the fluid removal associated with the multiple extractions. Correcting the group 4 values for the $\mathrm{F}$ content of the fluid over these specimens, the amount of $\mathrm{CaF}_{2}$-like deposits not removed by the bulk removal of crystals was $0.0195 \pm$ $0.0038 \mu \mathrm{mol}$. After a similar correction, the $\mathrm{F}$ remaining in the group 2 samples, which were extracted with a plaque-fluid-like solution containing pyrophosphate, was $0.0021 \pm 0.0020 \mu \mathrm{mol}$, while the F remaining in the group 3 samples, which were extracted with a solution containing both pyrophosphate and phosphate, was $0.0033 \pm 0.0015 \mu \mathrm{mol}$. The $\mathrm{F}$ amounts remaining in these groups were significantly different from the group 4 values $(p<0.001)$, but they were not different from each other. Most importantly, the losses of F from the extractions in groups 2 and 3 were $89 \pm 5.1 \%$ and $83 \pm 3.8 \%$, respectively, of the $\mathrm{F}$ in group 4 not lost by bulk crystal removal.

The masses of the 2 homogenized plaque aliquots collected at 30 and $60 \mathrm{~min}$ after the $\mathrm{F}$ rinse were not significantly different (table 1). Plaque fluid free $\mathrm{Ca}$ and $\mathrm{pH}$ were also not significantly different at these collection times (table 1). The plaque fluid free $\mathrm{F}$ decreased significantly $(\mathrm{p}<0.01)$ between the 30 - and 60 -min collections (table 2). Similarly, the total plaque F content of the unextracted plaque samples (aliquot 1) decreased between the 2 time points; however, the difference was not statistically significant (table 2). The correlation between the plaque fluid $\mathrm{F}$ or total plaque $\mathrm{F}$ values obtained at the 30 and 60-min collection times was significant $(\mathrm{p}<0.001$ for plaque fluid F; $\mathrm{p}<0.02$ for total plaque F). Most notably, the F contents of aliquot 2, which was equilibrated under conditions that remove all forms of calcium fluoride, and of aliquot 1 , which contained the total fluoride, were not significantly different at either time point (table 2). In fact, the F contents of aliquots 1 and 2 are nearly identical.

\section{Discussion}

The similarity of the masses of the plaque aliquots at either collection time should obviate any concerns that the results observed were influenced by the amount of sample collected (table 1). The values for plaque fluid free $\mathrm{Ca}^{2+}, \mathrm{pH}$, total plaque $\mathrm{F}$ and plaque fluid $\mathrm{F}$ (tables 1,2 ) are

$\mathrm{No} \mathrm{CaF}_{2}$ in Plaque Shortly after $\mathrm{NaF}$ Rinse nominally similar to those previously obtained [Vogel et al., 1992, 1998, 2000a-c, 2001, 2002, 2006, 2008b]. As expected, the plaque fluid $\mathrm{F}$ rapidly decreased between the 30- and 60-min collections; however, in agreement with previous studies [Vogel et al., 2000a], only a small and not statistically significant decrease in the total F content of the plaque (aliquot 1 ) was observed in the plaque samples collected at these time points. The high correlation of the $\mathrm{F}$ between the 30- and 60-min collection times for both the total plaque and plaque fluid values suggests that the F distribution pattern from these subjects was consistent, at least over a short collection interval.

The in vitro test of the procedure demonstrated that more than $80 \%$ of the $\mathrm{CaF}_{2}$-like crystals were extracted by the plaque-like test solutions. Since the F content of these test samples was more than 10 times the $\mathrm{F}$ in the plaque samples, these findings support the effectiveness of the procedure used in this study for extracting $\mathrm{CaF}_{2}$ like deposits from plaque samples. Hence, the similarity (within 3\%) of the $\mathrm{F}$ in aliquots 1 and 2 indicates that $\mathrm{CaF}_{2}$-like deposits were not found in the plaque within 30 min of a $\mathrm{NaF}$ rinse; the plaque $\mathrm{F}$ reservoirs appear to be entirely in the form of biological/bacterial Ca-F. There are, however, some caveats that should be noted. First, some $\mathrm{CaF}_{2}$-like deposits could initially have been formed and then dissolved. The dissolving deposits could be lost to saliva or converted to plaque bacterial Ca-F during the $0.5 \mathrm{~h}$ before the equilibration was begun [Whitford et al., 2005]. However, this dissolution would negate the putative role of $\mathrm{CaF}_{2}$ as a persistent source of plaque fluid $\mathrm{F}$. It should be noted that it is also possible, in view of the high concentration of phosphate in plaque fluid [Margolis et al., 1993; Vogel et al., 2000b, 2000c, 2002], that $\mathrm{CaF}_{2}$-like deposits could have dissolved to form FAp, which would not be extractable by the plaque-fluid-like solution and therefore could not be distinguished from bacterial Ca-F in this study. Oral fluids, however, contain high concentrations of inhibitors [Hay et al., 1984; Nancollas and Johnsson, 1994] that strongly repress FAp mineralization. Second, it is also possible that the 0.5 -hour storage of the plaque was not sufficient for the $\mathrm{F}$ in the plaque mass to come to equilibrium with the plaque fluid. However, if this equilibrium was not achieved, the subsequent equilibration of aliquot 2 with a plaque-fluid-like solution would have removed bacterial Ca-F from this aliquot or induced its formation. Either result should increase the difference between the 2 aliquots, contrary to the results observed.

The finding that no $\mathrm{CaF}_{2}$-like deposits are found in the plaque shortly after a $228 \mu \mathrm{g} / \mathrm{g} \mathrm{F}(0.05 \% \mathrm{NaF})$ rinse 
may seem surprising, given that saliva and plaque fluid are highly supersaturated (i.e. $\left\{\mathrm{Ca}^{2+}\right\} \times\left\{\mathrm{F}^{-}\right\}^{2}>3 \times 10^{-11}$ ) with respect to this mineral for a few (approx. 5) minutes after the administration of a 228-ppm F rinse [Øgaard, 2001; Whitford et al., 2005]. However, the $\left\{\mathrm{Ca}^{2+}\right\} \times\left\{\mathrm{F}^{-}\right\}^{2}$ required for the spontaneous nucleation of this mineral is approximately $10^{-7.5}$, which is 3.5 orders of magnitude higher than the above value [Larsen and Jensen, 1994]. Although the value of $\left\{\mathrm{Ca}^{2+}\right\} \times\left\{\mathrm{F}^{-}\right\}^{2}$ for nucleation may be diminished in the presence of a substrate such as plaque [Larsen and Richards, 2001], the low amount of free $\mathrm{Ca}$ in saliva and plaque fluid (less than 1/12 the amount of $\mathrm{F}$ applied in these studies) not only greatly limits the amount of $\mathrm{CaF}_{2}$-like deposits that can be formed in these substrates, but also implies that any formation of these deposits will immediately depress the value of $\left\{\mathrm{Ca}^{2+}\right\} \times\left\{\mathrm{F}^{-}\right\}^{2}$ below the value needed for further precipitation. With regard to the formation of $\mathrm{CaF}_{2}$-like precipitates in saliva, the small amount of this material formed at the low salivary Ca concentration (and neither swallowed nor expectorated) would be deposited primarily on the mucosa, whose surface is much larger than that of the plaque. With regard to plaque, it is possible that additional Ca could be released from the large plaque bacterial $\mathrm{Ca}$ stores during the formation of $\mathrm{CaF}_{2}$-like deposits. However, it seems unlikely that this process would be fast enough to form more than a small amount of these deposits before the fluoride activity falls (as noted above) below the level that is required for spontaneous precipitation. On the other hand, the mechanism of the reaction of $\mathrm{F}$ with bacterial $\mathrm{Ca}$ appears to occur without a complete extraction of $\mathrm{Ca}$ from plaque $\mathrm{Ca}$ binding sites [Rose et al., 1996], and hence is likely to be a relatively rapid process that should successfully compete with the formation of $\mathrm{CaF}_{2}$-like deposits.

The F rinse concentration employed here $(228 \mu \mathrm{g} / \mathrm{g})$ is about the same as that used in over-the-counter F rinses. This concentration is also similar to the $\mathrm{F}$ we have found in the expectorated saliva/dentifrice mixture ob- tained after a 1-min brushing with $1.5 \mathrm{~g}$ of an over-thecounter NaF dentifrice [Vogel, unpubl.]. Furthermore, the common dentifrice ingredient sodium lauryl sulfate has been shown to greatly reduce the formation of calcium fluoride [Barkvoll et al., 1988]. Hence, the results presented here suggest that biologically/bacterially bound $\mathrm{Ca}-\mathrm{F}$, rather than calcium fluoride or $\mathrm{CaF}_{2}$-like deposits, is the form of plaque $\mathrm{F}$ that releases this ion to plaque fluid shortly after the use of over-the-counter F dentifrices and rinses. The nature of this binding, however, requires further investigation; in agreement with previous data [Vogel et al., 1992, 2000a, 2000c, 2001, 2008b; Whitford et al., 2005; Tenuta et al., 2006], the amount of F held per milligram of plaque appears to be much higher than predicted from Ca-F binding studies using bacterial cultures [Rose et al., 1996].

This inability to form potentially more persistent calcium fluoride deposits, which appears to be due to the low concentration of oral fluid Ca, may account for the relatively rapid loss of $\mathrm{F}$ in plaque after the use of current over-the-counter topical $\mathrm{F}$ agents. It should be noted in this regard that (1) studies in which a Ca preapplication was used to ameliorate this situation have produced very large and persistent increases in both plaque fluid and salivary fluoride [Vogel et al., 2006, 2008a, 2008b], and that (2) preliminary studies [unpubl.] using modifications of the techniques described here confirm that the use of a Ca prerinse prior to a $\mathrm{F}$ rinse indeed forms large amounts of $\mathrm{CaF}_{2}$-like deposits.

\section{Acknowledgment}

This study was supported by a grant from the American Dental Association Foundation and by the United States Public Health Service Research grant No. DE16416 to the American Dental Association Foundation from the National Institutes of Health, National Institute of Dental and Craniofacial Research, and is part of the dental research program conducted by the National Institute of Standards and Technology in cooperation with the American Dental Association Foundation.

References

Arends J, Christoffersen J: Nature and role of loosely bound fluoride in dental caries. J Dent Res 1990;69(spec iss):601-605.

Barkvoll P, Rølla G, Lagerlöf F: Effect of sodium lauryl sulfate on the deposition of alkali-soluble fluoride on enamel in vitro. Caries Res 1988;22:139-144.

Bockris JOM, Reddy AKN: Modern Electrochemistry: Fundamentals of Electrodics, ed 2. New York, Plenum, 2000.
Christoffersen J, Christoffersen MR, Kibalczyc W, Perdok WG: Kinetics of dissolution and growth of calcium fluoride and effects of phosphate. Acta Odontol Scand 1988;46: 325-336.

Featherstone JD: The science and practice of caries prevention. J Am Dent Assoc 2000;131: 887-899. 
Grubbs FE, Beck G: Extension of sample sizes and percentage points for significance test of outlying observations. Technometrics 1972; 14:847-854.

-Hay DI, Smith DJ, Schluckebier SK, Moreno EC: Relationship between concentration of human salivary statherin and inhibition of calcium phosphate precipitation in stimulated human parotid saliva. J Dent Res 1984;63: 857-863.

Lagerlöf F, Saxegaard E, Barkvoll P, Rølla G: Effects of inorganic orthophosphate and pyrophosphate on dissolution of calcium fluoride in water. J Dent Res 1988;67:447-449.

Larsen MJ, Jensen SJ: Experiments on the initiation of calcium fluoride formation with reference to the solubility of dental enamel and brushite. Arch Oral Biol 1994;39:23-27.

Larsen MJ, Ravnholt G: Dissolution of various calcium fluoride preparations in inorganic solutions and in stimulated human saliva. Caries Res 1994;28:447-454.

Larsen MJ, Richards A: The influence of saliva on the formation of calcium fluoride-like material on human dental enamel. Caries Res 2001;35:57-60.

-Margolis HC, Moreno EC: Physicochemical perspectives on the cariostatic mechanisms of systemic and topical fluorides. J Dent Res 1990;69(spec iss):606-613.

-Margolis HC, Zhang YP, van Houte J, Moreno EC: Effect of sucrose concentration on the cariogenic potential of pooled plaque fluid from caries-free and caries-positive individuals. Caries Res 1993;27:467-473.

Matsuo S, Rølla G, Lagerlöf F: Effect of fluoride addition on ionized calcium in salivary sediment and in saliva containing various amounts of solid calcium fluoride. Scand J Dent Res 1990;98:482-485.

McCann HG: The solubility of fluorapatite and its relationship to that of calcium fluoride. Arch Oral Biol 1968;12:987-1001.

-Moreno EC, Aoba T, Margolis HC: Pyrophosphate adsorption onto hydroxyapatite and its inhibition of crystal growth. Compend Suppl 1987;8:S256-S266.
Nancollas GH, Johnsson MA: Calculus formation and inhibition. Adv Dent Res 1994;8: 307-311.

Øgaard $\mathrm{B}: \mathrm{CaF}_{2}$ formation: cariostatic properties and factors of enhancing the effect. Caries Res 2001;35(suppl 1):40-44.

Rølla G, Saxegaard E: Critical evaluation of the composition and use of topical fluorides with emphasis on the role of calcium fluoride in caries inhibition. J Dent Res 1990;69 (spec iss):780-785.

Rose RK, Shellis RP, Lee AR: The role of cation bridging in microbial fluoride binding. Caries Res 1996;30:458-464.

ten Cate JM: In vitro studies on the effects of fluoride on de- and remineralization. J Dent Res 1990;69(spec iss):614-619.

ten Cate JM: Review on fluoride, with special emphasis on calcium fluoride mechanisms in caries prevention. Eur J Oral Sci 1997;105: 461-465.

Tenuta LM, Del Bel Cury AA, Bortolin MC, Vogel GL, Cury JA: $\mathrm{Ca}, \mathrm{Pi}$, and $\mathrm{F}$ in the fluid of biofilm formed under sucrose. J Dent Res 2006;85:834-838.

Vogel GL, Carey CM, Chow LC, Ekstrand J: Fluoride analysis in nanoliter- and microliter-size fluid samples. J Dent Res 1990a;69 (spec iss):522-528.

-Vogel GL, Carey CM, Chow LC, Tatevossian A: Micro-analysis of plaque fluid from singlesite fasted plaque. J Dent Res 1990b;69:13161323.

Vogel GL, Chow LC, Brown WE: A microanalytical procedure for the determination of calcium, phosphate and fluoride in enamel biopsies. Caries Res 1983;17:23-31.

Vogel GL, Chow LC, Carey CM: Calcium prerinse greatly increases overnight salivary fluoride after a 228-ppm fluoride rinse. Caries Res 2008a;42:401-404.

Vogel GL, Mao Y, Carey CM, Chow LC, Takagi S: In vivo fluoride concentrations measured for two hours after a NaF or a novel two-solution rinse. J Dent Res 1992;71:448-452.
Vogel GL, Mao Y, Chow LC, Proskin HM: Fluoride in plaque fluid, plaque, and saliva measured for two hours after a NaF or NaMFP rinse. Caries Res 2000a;34:404-411.

Vogel GL, Schumacher GE, Chow LC, Takagi S, Carey CM: Ca pre-rinse greatly increases plaque and plaque fluid. J Dent Res 2008b; 87:466-469.

Vogel GL, Shim D, Schumacher GE, Carey CM, Chow LC, Takagi S: Salivary fluoride from fluoride dentifrices or rinses after use of a calcium pre-rinse or calcium dentifrice. Caries Res 2006;40:449-454.

Vogel GL, Zhang Z, Carey CM, Ly A, Chow LC, Proskin HM: Composition of plaque and saliva following a sucrose challenge and use of an $\alpha$-tricalcium-phosphate-containing chewing gum. J Dent Res 1998;77:518524.

Vogel GL, Zhang Z, Carey CM, Ly A, Chow LC, Proskin HM: Composition of plaque and saliva following use of an $\alpha$-tricalcium-phosphate-containing chewing gum and a subsequent sucrose challenge. J Dent Res 2000b;79: 58-62.

Vogel GL, Zhang Z, Chow LC, Schumacher GE: Effect of a water rinse on 'labile' fluoride and other ions in plaque and saliva before and after conventional and experimental fluoride rinses. Caries Res 2001;35:116-124.

Vogel GL, Zhang Z, Chow LC, Schumacher GE: Changes in lactate and other ions in plaque and saliva after a fluoride rinse and subsequent sucrose administration. Caries Res 2002;36:44-52.

Vogel GL, Zhang Z, Chow LC, Schumacher GE, Banting D: Effect of in vitro acidification on plaque fluid composition with and without a $\mathrm{NaF}$ or a controlled-release fluoride rinse. J Dent Res 2000c;79:983-990.

Whitford GM, Buzalaf MAR, Bijella MFB, Waller JL: Plaque fluoride concentrations in a community without water fluoridation: effects of calcium and use of a fluoride or placebo dentifrice. Caries Res 2005;39:100-107. 